\title{
The dual role of the action researcher
}

\section{Marianne Trondsen M.A.*}

Email:marianne.trondsen@telemed.no

Norwegian Centre for Telemedicine

University Hospital of Northern Norway

P.O. Box 35

N-9038 Troms $\emptyset$

Norway

Department of Sociology

University of Troms $\varnothing$

N-9038 Troms $\varnothing$

Norway

\section{Anne-Grete Sandaunet Ph.D.}

Email: agsand@online.no

Department of Sociology

University of Troms $\varnothing$

N-9038 Troms $\varnothing$

* Corresponding author:

Marianne Trondsen

Fax: +47 77754098

\section{Word count:}

Included title page, abstract, references, lessons learned and acknowledgements: 8518 


\begin{abstract}
This article aims to provide more insight into advantages and challenges of conducting action research with the intention to improve health care. Action research is distinctive in the sense that the researcher has a dual role as both researcher and implementer of the program studied. The article is based on two Norwegian action oriented studies that aimed to explore the potential role of online self-help groups for breast cancer patients and adolescents with mentally ill parents respectively. We argue that action research can contribute both to the generation of knowledge, as well as a greater sense of ownership to the program among those who are intended to use it. Nonetheless, a potential conflict between the researcher's pursuit of data, and ethical considerations became apparent in the contexts studied here. Bearing these challenges in mind, we still conclude that action research offers an important contribution for the further development of health care services.
\end{abstract}

Word count abstract: 152

Keywords: Action research, dual role, Norway, online self-help groups 


\section{Introduction}

This article addresses action research as a source of knowledge for organising and developing health care. Action research enters into the domain of applied research and describes a whole family of methods which are participative, grounded in experience, action-oriented and that responds to issues that are of pressing concern to people (Ladkin, 2007; Reason \& Bradbury, 2006b). A crucial aim is the mutual learning that takes place between the owners of the internal problem and the outside facilitators or researchers (Finne, Levin, \& Nilssen, 1995). The dual role of the researcher as both researcher and implementer is characteristic for the approach (Olsen \& Lindøe, 2004).

During the last years, action research has gained increased attention in health care research as a potential approach to develop this complex field (Cullen, 1998; Flicker, Maley, Ridgley, Biscope, Lombardo et al,, 2008 Khanlou \& Peter, 2005; Morrison \& Lilford, 2001). Cullen (1998) describes an organisational re-engineering that will provide the spaces and contexts in which action research can re-invent itself. This is related to the expansion of health care systems, the introduction of new technologies and the emphasis placed on the user perspective in health care. The complexity of these processes is actualizing use of flexible, participative and process-oriented methods in the efforts to improve health care (Cullen, 1998).

Based on two Norwegian action-oriented studies of the potential role of online self-help groups, the aim of this article is to offer insights into the advantages and challenges of action research as a source of research data, and as a strategy for change. 


\section{Action Research}

The concept "action research" was first introduced by Kurt Lewin in conjunction with his search for methods that were suitable for dealing with social problems (Ladkin, 2007; Reason \& Bradbury, 2006a). The approach has been used across different fields, and has been developed at the interface between the social and organizational sciences and political movements (op cit).

Morrison and Lilford (2001) have summed up the main characteristics of action research by what they describe as its five "key tenets". The first of these is the flexible planning tenet. This implies that the detailed content and direction of a research project is not determined at the outset, but is continuously under review during the work process. The second tenet is the iterative cycle, which means that the research activity proceeds as a cyclic process of considering what the problem is, taking action and reflection (op cit). This tenet views the researcher as an implementer or "changing agent" who works to realise the "program" in question (Finne, Levin, \& Nilssen, 1995; Olsen \& Lindøe, 2004). It further requires a continuous dialogue with all the interested parties.

Morrison and Lilford's (2001) third tenet, the subjective meaning tenet, emphasises the situational definitions and subjective meanings of those who are implicated in the problem being researched. The forth tenet is the simultaneous improvement, which emphasise that the research project must be set out to change the problem situation for the better while in the process of researching it. It then opens up for the immediate use of data and thereby for adjustments in the program studied. This means that action research is also a way of intervening to solve a problem, not only an approach to research. The researcher - as implementer - contributes to the undertaking of these changes. Their fifth and last point is the 
unique context tenet. This point stresses the necessity of taking into account the complex, ever-changing and unique nature of the social context in which the study is carried out.

As indicated by this overview, action research has several similarities with formative evaluation. Both action research and formative evaluation aim to form the "thing" being studied (Patton, 1990). What is distinctive for action research is the dual role of the researcher who acts both to increase knowledge within the research community, and as an implementer of the program. As implementer, the researcher contributes to realise the intentions of the program and to the circulation of knowledge within the local context. This activity forms the basis of the cyclical process that characterises action research. In formative evaluation, the researcher has a role that is more distinct from the people or organisation being researched (Patton, 1990).

It is the dual role of the action researcher that functions as a point of departure for this reflection on the advantages and challenges related to the use of action research. We outline how the researcher enters into the role as implementer of a program and discuss the consequences of wearing these different "hats". This oscillation between different roles has been addressed in previous research, see for example (Cook, 2006; Olsen \& Lindøe, 2004; Silverman, Taylor, \& Crawford, 2008; van Eyk, Baum, \& Blandford, 2001). Within this literature, both the validity of the research conducted (Cook, 2006) and the legitimacy of the dual role of the researcher among the formal stakeholders and those being researched (Olsen \& Lindøe, 2004; Silverman, Taylor, \& Crawford, 2008; van Eyk, Baum, \& Blandford, 2001) have been discussed. Through the following reflections on the experiences from two Norwegian action research studies which had the aim to improve health care, our goal here is to contribute to this literature. 


\section{Material}

The two studies on which this article builds were developed on the Norwegian Centre for Telemedicine (NCT). NCT gathers, produces and disseminates knowledge about telemedicine and ehealth, and aims to ensure the integration of telemedicine services. The centre is located within the formal health care system, as a division within the University Hospital of Northern Norway.

Both studies involved collaboration with other actors in the health care delivery in Norway. Establishment and management of an online self-help group was further part of both studies. Online self-help groups are social networks formed or facilitated through electronic media, and they appear as mailing lists, newsgroups or UseNet discussion forums, web-based discussion forums and live chat-rooms (Burrows, Nettleton, Pleace, Loader, \& Muncer, 2000). Self-help groups, both face-to-face based and on the Internet, exist in a wide range of styles and structures. Some are also professionally facilitated, but it is demonstrated that groups that define themselves as self-help tend to be viewed by members as self-help (Davison, Pennebaker, \& Dickerson, 2000).

Previous research has emphasised the potential of online self-help groups to help people cope more effectively with their health problems (Bar-Lev, 2008; Klemm, Bunnell, Cullen, Soneji, Gibbons et al., 2003; Kummervold, Gammon, Bergvik, Johnsen, Hasvold et al., 2002). They represent a "bottom-up" production of welfare (Burrows, Nettleton, Pleace, Loader, \& Muncer, 2000), which is a key issue to social policies in Norway and other western welfare states. The multiplied possibilities to exchange information and the disembodied context offered by the Internet have further been emphasised as potential benefits (Hardey, 1999; Walther \& Boyd, 2002). More knowledge about the potential role of online self-help groups is 
still needed (Bar-Lev, 2008; Eysenbach, Powell, Englesakis, Rizo, \& Stern, 2004), and the aim of the studies discussed in this article has been to make a contribution toward increasing this knowledge. Our research questions addressed whether i) the multiplied access to information and other peoples' experiences and ii) the disembodied context on the Internet, influenced on how women with breast cancer and youth who live with a mentally ill parent coped with their situation.

Both groups that were established were password-protected and the participants were anonymous to each other. The first study was initiated in 2001 and aimed to explore the potential of online self-help groups in breast cancer rehabilitation. This study was conducted by the second author of this article: Anne-Grete Sandaunet. The initiation of the study took place in a context of technology optimism and was based on promising prospects for ehealth (Eysenbach, 2000; Ferguson, 2000). Further, the health authorities in Norway sensed a need to keep pace with the emergence of more active and involved health care users who are ready to assume more responsibility for their health (The Ministry of Health and Social Affairs, 2001). The study was conducted in collaboration between the Norwegian Centre for Telemedicine (NCT), the Norwegian Cancer Society (NCS) and the Norwegian Breast Cancer Society, which is affiliated to NCS.

Women with breast cancer represent a potential target group for online self-help groups. Cancer is an illness that elicits considerable distress (Shapiro, Lopez, Scwarz, Bootzin, Figueredo et al., 2001), and women with breast cancer are also among the frequent users of online self-help groups more generally (Davison, Pennebaker, \& Dickerson, 2000). A newsgroup was established through the website of the Norwegian Cancer Association (www.kreft.no), and was accessible between October 2003 and March 2005. At the time of 
the start up of the study, this group and a group for young people that were diagnosed with cancer were the only interactive services provided by the NCS. Their remaining web-based services for cancer patients and their relatives were sites with cancer related information. Participants were recruited through media and through information distributed by the Norwegian Cancer Society and the Norwegian Breast Cancer Association. Forty women participated in the study. The NCS withdrew as a participant in the study about 6 months after the group was established. The organisation considered the interest of the group among women with breast cancer to be modest and decided not to implement online self help groups as part of their ordinary services at that time.

The aim of the second study was to explore the prevention potential of online self-help groups for adolescents who live with a mentally ill parent, and was conducted by the first author of this article; Marianne Trondsen. This study was initiated in 2004, three years later than the breast cancer study. Research has shown that children who live with a mentally ill parent are at risk in terms of their cognitive, emotional and social development (Rutter \& Quinton, 1984; Smith, 2004). They also tend to be invisible and neglected in the mental health care system (Gladstone Mc Connell, Boydell, \& McKeever, 2006). Further, the lack of interventions to prevent illness or promote their health is well documented, and indicates a need for development of creative interventions and strategies (Mordoch \& Hall, 2002). Young people are further early adopters of the Internet (Skinner, Biscope, \& Poland, 2003), and use of technology is considered to have potential as a strategy for engaging youth in health promotion (Flicker, Maley, Ridgley, Biscope, Lombardo et al., 2008).

In this study, the Norwegian Centre for Telemedicine collaborated with the Child- and Adolescents Psychiatric Clinic R\&D at Sørlandet Hospital in Norway. This clinic had an 
already existing website; www.morild.org, which was established in 2001 as a prevention strategy and support for children and youth who have parents with mentally health problems. It was introduced as an information service, but has gradually been extended to include interactive services. In 2004, a “question-answer" service was established in which health professionals responded to questions from children and youth.

Through the collaboration between Sørlandet Hospital and the Norwegian Centre for Telemedicine, and the start-up of the study discussed here, the website www.morild.org was developed further by establishing an online self-help group for adolescents (15-18 years old). The group was accessible in December 2005. All the participants in the study were selfrecruited by information through the website www.morild.org, other websites for youth, different types of media, health professionals and posters at schools. The online group was titled "the Talking-room", and sixteen adolescents have participated in the study. The service was established as a permanent service on Sørlandet Hospital's website www.morild.org, when the research was completed (December 2007).

Both studies were approved by the Regional Committee for Medical Research Ethics and the Norwegian Social Science Data Services. The breast cancer group was accessible during 16 months, and the youth group was accessible for two years. During these periods, participants in the breast cancer group posted 1114 messages, and participants in the youth group posted 601 messages. The research material was gathered through participant observation in the groups, and through face-to-face based qualitative interviews of respectively 25 study participants in the breast cancer study and 13 study participants in the youth study. We analysed the material through a continuous alternation between the empirical findings, 
previous research and theoretical concepts. In general terms, this approach to the research material is typical for qualitative research (Kvale, 1996).

There was an active dialogue between the researchers and the collaborating organisations throughout the planning phase, the implementation and the management of the online selfhelp groups. The management of the service included an administrative responsibility and a controlling function that was conducted in accordance with our clarifications with each participating organisation. This responsibility is comparable to the moderator-role that is present in many online self-help groups.

Even though there is a wealth of commercial and grass roots driven health care services on the Internet, the development and implementation of ehealth services within health care is still in its early phase. During the development of both studies, there was a need for clarifying how to account for ethical issues, or in other words, how we could prevent that the participants in these studies were not exposed to any harm. This work was partly prompted by our dialogue with the Regional Committee of Medical Research Ethics. This committee is a resource of competence in ethics and must be consulted by researchers who work in the medical field (The Regional Committees for Medical Research Ethics in Norway, 2006).

Our considerations resulted in a decision to monitor daily the activity in the groups. We also made considerable efforts to inform potential users that the services were not intended to function as an emergency aid, and further that they could encounter the disclosure of difficult details in these groups. We underscored that we, the moderators of the groups, were not health professionals. We also informed them that their postings were not necessarily read once they 
were left in the forums. Both web-pages were further equipped with a link to a site that contained information about services that could offer immediate support.

In both studies, a reference group was established consisting of technical, juridical and clinical expertise. We could contact this group if we experienced problems related to the activity in the groups. In the breast cancer study, the leader of the "Cancer Line", a nurse, represented one of the members in the reference group. The Cancer Line is a telephone and email based service to people who have questions about cancer. In the youth study the reference group consisted of health professionals who had competence in mental health care and who where experienced in working with children and youth in crises. They were also accustomed to using the Internet as a communication tool to respond to children in a difficult life situation.

A role of the researcher as mandatory reporter was not considered as relevant in these studies. A mandatory reporter is a health professional who is required to report to health authorities when vulnerable populations are exposed, or suspected to be exposed to, a risk of serious harm. The researchers in these studies were not health professionals with clinical competence, and could thereby not enter a role as mandatory reporter. However, the physical distance to group members and the anonymous communication that characterises online communication also raise the question whether this level of surveillance can be realised in the online context more generally.

In addition to our controlling function, and of particular importance here, we worked to ensure an optimal function of the service. It is this dimension of the implementing role that is more closely examined in this article. 


\section{Ensuring an optimal function of the services}

Our efforts to ensure an optimal function of the services are traceable through two main activities; first, we worked to facilitate use of the service and to ensure a supportive community in the group. This work was based on our initial ideas about how to establish a well-functioning service. Second, these efforts to ensure an optimal function included an immediate use of data; the experiences were continuously assessed and incorporated into the further development of the actual service.

\subsection{Facilitating use of the services and ensuring a supporting community}

\subsubsection{Facilitating use of the services}

In accordance with our intention to encourage use of the services, we were continuously aware of how it was used. In the breast cancer study, the researcher noted that there were several participants that did not write postings in the group. She contacted the actual participants to ask if there were any practical problems related to their participation that she could help them with, or if there were other reasons for their absence. The reason to choose this form of "follow-up" was related to the group of women studied. The majority of the participants in this study were about fifty years old. Even though most of them described themselves as comfortable with using the Internet, only a few had used newsgroups or chatrooms. In addition, they needed a password to access the group, which potentially could complicate their use of the service. It was therefore reasonable to assume that their absence could be related to difficulties of use. By calling them and asking them if they needed help, the researcher could contribute to minimising such barriers. However, their absence was only to a very modest degree related to such difficulties. Rather, the experience of not "fitting in" emerged as an important reason to not participate or withdraw from this group and directed 
attention both to the presentations of illness that these women felt comfortable with, but also to how the group was organised and leaded (Sandaunet, 2008).

An interesting point is that some participants sent an email to the researcher before she contacted them to ask why they did not use the group. In these emails, and on their own initiative, the participants apologised for their absence. In her response, the researcher then answered that it was important to eliminate practical challenges related to group participation, but that it was crucial for the research conducted that they used the group in accordance with their own needs.

The participants in the youth group were all familiar with using forum and chat-rooms on the Internet. The challenge in the youth group was that the number of participants was low during the initial period and that it appeared difficult to start "talking" with each other. To facilitate interaction, the researcher wrote postings in the forum asking the users about how to increase the activity, gave them input on themes that could be addressed, and asked them if they had ideas for recruiting more participants. After a while a girl started writing, and the others followed suit. Furthermore, some participants commented in the group that they appreciated the researcher's initiative. This latter example can appear as use of "common sense"; the researcher recognised the need for someone to initiate a conversation, which is often a challenge within contexts in which strangers are gathered. It is however important to be aware that we, based on optimistic accounts of the liberating effect of anonymous communication on the Internet (Kummervold, Gammon, Bergvik, Johnsen, Hasvold et al., 2002; Walther \& Boyd, 2002), did expect that the initiation of a conversation would take place more smoothly. 


\subsubsection{Contributing to a supportive community}

Our work to ensure a supportive environment in the group included efforts to adjust for ease, and to provide a feeling of confidence. We did this based on the idea that talking openly in the company of other people in a similar situation was helpful for psychosocial wellbeing (Lieberman \& Goldstein, 2005).

Both researchers were active in efforts to create a friendly environment, for example by welcoming the participants in the beginning of the study period and inviting them to talk openly about their situation. This invitation was also expressed in the information letter about the services. In the breast cancer study, the participants were still asked to warn the others in the heading, or in the first sentences in the posting, if they thought that the content of the posting might be hard to read for other participants. Such requests for considerate behaviour are common also in Alcoholics Anonymous (AA) groups (Waldron, Lavitt, \& Kelley, 2000), and is not only part of the establishment of this particular self-help group. Some women expressed anxiety for doing "something wrong" by addressing the dark side of breast cancer, for example the experience of living with spread. In these cases, the researcher had to underscore for them that such issues were welcome when they were introduced in accordance with the customs of the group. As outlined in the latter section, the participants in the breast cancer study were also informed about the possibility of encountering difficult details about breast cancer before they consented to participate in the group. Based on her dialogue with the Regional Committee for Medical Research Ethics, the researcher still felt an obligation to be particularly aware of how difficult issues, such as spread and the life-threatening aspect of breast cancer were addressed by the women in the group. She interpreted the insecurity expressed by some of the group members as a call for more clarity about how they could 
address these issues within the group conversation. It thereby contributed to an increased attention to the leadership of the group.

At some occasions, both researchers experienced contrasting needs between the "researcherperspective" of gaining information and the work to ensure a supporting community. In the breast cancer study, the researcher entered and partly interrupted a conversation in which one woman told about an experience of serious violence. This episode was at this time reported and under investigation by the police, but the woman felt that she was loosing the grip of her life. She asked the others for support. From a researcher's point of view, it could be interesting to observe how the group handled such openness and despair. On the other hand, there was a fear that this might be overwhelming for other women in the group, even though some of them had responded to the woman with understanding comments. For the researcher, the woman's problem further appeared very fundamental and serious. She contacted both the woman and a trained clinician in the reference group and later advised the woman about how to contact a resource centre for abused women. The researcher commented carefully that the cancer group might not have the insights that were necessary to help her. The researcher then interrupted a potential dialogue on this issue within the group.

In the youth group, there were also episodes in which the researcher experienced that the need for gaining information appeared at odds with ethical considerations. For example, one girl told the others about an episode of self-cutting. The researcher and the responsible organisation were prepared for the chance of this serious issue to be introduced. Self-injury, such as self-cutting, appears to be an increasing tendency among adolescents, particularly by youths who are in a difficult situation (Evans, Hawton, \& Rodham, 2005; Hawton, Hall, Simkin, Bale, Bond al., 2003; Nock \& Teper, 2007). In addition, the chance of the 
introduction of this and other difficult issues was included in the ethical considerations that took place in the planning phase of the study. In such cases, the researcher would inform the trained clinicians in the reference group and discuss how to respond adequately in the present situation.

Being aware of her ethical responsibility the researcher considered it as necessary to try to prevent a destructive discussion about the issue of self-cutting. Previous research has directed attention to the risk of idealizing harmful behaviour in online self-help groups (Gavin, Rodham, \& Poyer, 2008; Johnsen, Rosenvinge, \& Gammon, 2002). In order to take care of the girl and to follow up this discussion adequately, the researcher immediately contacted the health professionals in the reference group. Together they decided that a trained clinician from the reference-group should intervene in the discussion, by writing an answer that addressed both this girl and the other participants. It is important to be aware that the researcher and the leader of the reference group knew, through previous contact, that the girl already had told her psychologist about this episode of self-cutting. The trained clinician continued following up for a while through therapeutic advices and knowledge about selfinjury. Through this professional involvement, the aim was to ensure an edifying and constructive dialogue about this serious issue and also to give professional support to the youths in how to handle their problems adequately.

There is also a final point that needs attention in relation to our efforts to facilitate the emergence of a supportive community in these groups. Some of the participants were active contributors to this work, for example by being aware of responding to others when they wrote postings in the group. These participants' wish to contribute to the creation of a wellfunctioning service was apparent and, to a degree, explicitly expressed. 


\subsection{Immediate use of data}

While the above description demonstrates our efforts to realise our initial ideas of a wellfunctioning service, we also continuously assessed the experiences and incorporated these into our further work. The users of the services were active participants in these discussions, while the collaborating organisations varied in the nature and extent of their involvement.

One important experience made in both studies was that the leadership of the groups needed to be further developed. In the initial phase, both researchers behaved more like practical administrators of the groups. This was in accordance with an intention to adhere to a self-help approach in which the conversation was governed by the participants. One example of this is that we welcomed the participants in the first posting in the group, but also told them that the "the stage was theirs". During the study period, both researchers changed their behaviours in the groups. The researcher in the breast cancer study experienced that her initial approach, within which she tried to be a kind of "invisible facilitator" in the group, appeared to be more confusing than liberating for the participating women. As commented previously, some of them did at some occasions express insecurity about how to behave. The researcher gradually entered a more salient role as "hostess" of the group, such as welcoming each new member and being active in responding to participants who feared that they had done something wrong. One of the active users of the breast cancer group was further asked to enter a role as co-editor. This woman was an experienced and engaged user of online self-help groups and filled a kind of "veteran" function that is argued to be important in self-help groups (Till, 2003). On the whole, the leader function of the group was made more visible.

In the youth study, the researcher also gradually entered a more active role as "hostess" of the group, welcoming new participants and also responding to the participants if they needed 
some kind of general information. She also noted that the youths sometimes asked questions in the group about medical, psychiatric or juridical issues, which none of the other youths were able to respond to. Some of these questions were also directed to the researcher. This experience raised the question whether there was need for a health professional, which could be available in these situations. The researcher discussed this issue with the leader of the reference group. She also asked the youths in the self-help group about their view on having a health professional available to answer such questions.

After this discussion, the researcher continued as moderator of the group. The leader of the reference group entered the role as a professional consultant who could be available for the youths if they asked for expert knowledge. This adjustment has also been incorporated into the following establishment of the Talking-room as a permanent service. However, the intention to create a self-help context is still underpinning the management of the service.

It is interesting to note that the leader of the reference group commented that her participation as a professional consultant facilitated a sense of engagement and ownership to the service. This active involvement made her familiar with the participants, and gave her deeper insight in how to run online self-help groups. Her sense of ownership became particularly visible through the process of transferring the service from a pilot project to a permanent service.

The above examples from the studies illustrate how the researcher in each study actively built on the experiences gained and how the groups were transformed on the basis of this knowledge. The experienced need to develop further the leader function fits with previous research that has directed attention to the leadership and structure of online self-help groups (Lieberman \& Russo, 2001; Till 2003). Another example can be drawn from the breast cancer 
study. Some of the participants experienced the mix between women who had experienced the spread of the cancer and newly diagnosed women as difficult. They suggested that it should be a clearer divide between topics that were related to spread, and other topics. Their response raised the question whether it was necessary to change the service. Following discussions, it was decided against separating the spreading issues into a separate forum, but instead start a topic with the heading "living with spread" that others could easily avoid.

This again illustrates the types of dilemmas that an action oriented researcher can encounter between a need for knowledge and the ethical responsibility towards the study participants.

\section{Discussion}

Based on the experiences from these two studies, we consider three points as crucial for the further debate on challenges and advantages of conducting action research with the intention to improve health care. First, we argue that the role of the researcher as also implementer of a program provides a unique possibility to explore the social and cultural context in which such new services are introduced. In the two studies outlined in this article, we were both active in our efforts to facilitate use of the service. Through this involvement, we gained further insight into how the participants coped with their situation and about the role of the online context. For example, based on her efforts to facilitate use of the online group and the women's response to this effort, the second author of this article, Anne-Grete Sandaunet, raised the question whether it is necessary to take more account of a need to "leave the illness behind" in the further debate on the potential role of online self-help groups in breast cancer rehabilitation (Sandaunet, 2008). This argument adds some interesting questions towards the prominent image of the new active and involved health care user (The Ministry of Health and Social Affairs, 2001). 
In accordance with Morrison and Lilford (2001), we also want to argue that the cyclic activities of action research can be particularly valuable. In both studies, we experienced a need for a more salient leadership of the online self-help groups than was incorporated in our initial ideas about how such groups should be organised. Through our role as implementers we could respond effectively to this experience. In turn, we could "dive" further into it by rearranging the leadership in what we considered as more suitable to the group studied, and gain further knowledge of how it functioned. We experienced that crucial characteristics of offline communication where not necessarily eliminated in the disembodied context on the Internet (see, for example, Sandaunet, in press). This experience affirms recent research that tones down the "distinctiveness" of online communication (Rier, 2007), and which is an issue of considerable interest in Internet research (Bar-Lev, 2008; Hardey, 2002; Rier, 2007).

It is important to be aware that the conception of the researcher as "co-constructor" of data (Alvesson \& Sköldberg, 2000; Burawoy, 1998) frames our argument that the action research framework offers an increased possibility to gain knowledge about the social and cultural context in which new services are introduced. Within this perspective, the idea of a reality "out there" that can be grasped is replaced by a view that accounts for an influence of the researcher and the research-context in knowledge generation. The peculiar character of action research as a method for gaining knowledge is thereby toned down. At the same time, the active and deliberate involvement of the researcher in the contexts being studied still claims awareness to the validity of the research conducted. Cook (2006) enters this debate and argues that in her case, the use of collaborative action research offered a means of getting close to finding out what might produce new understandings. Additionally, Burawoy (1998) argues that institutions reveal as much about themselves when they face the unexpected as well as the routine. "Institutions", in this case, may as well refer to established patterns of reactions and 
modes of acting. The active involvement of the researcher should therefore not necessarily be considered as a "threat" to the validity of the research conducted, but also as a dimension that can produce more insight. The important point here is that the active involvement of the researcher requires critical subjectivity (Ladkin, 2007) and a commitment to rigorously question and examine one's own position. One illustration of how such reflections were included in these studies is found in one of the papers that are based on the breast cancer study (Sandaunet, in press). In this paper the author suggests that dominant offline discourses about breast cancer are replicated in the online context. She further discusses how her own behaviour in the group contributed to this process, but concludes that the replication of dominant discourses is more fully illuminated by other dimensions.

Another question that can be raised in relation to the knowledge produced in these two studies, however, is how usable this context-bounded insight can be in developing future useroriented services. This is an important and interesting discussion, but also a discussion that concerns the usefulness of qualitative research more generally, and which we do not intend to enter here. The limited possibilities of generalising qualitative research are further debated. There are qualitative researchers who claim that such context-bounded insight can be available for some forms of generalisation. For a further introduction into this ongoing debate, see Payne and Williams (2005) and Sandelowski (2004).

Leaving the reflection on the knowledge production in action oriented studies our second point about challenges and advantages of conducting action research concerns the relationship to the stakeholders. In accordance with previous research (Silverman, Taylor, \& Crawford, 2008; van Eyk, Baum, \& Blandford, 2001), our argument is that the cyclical process that is connected to the action research framework can adjust for a close and maintained dialogue 
between the researcher and the collaborating organisations. The study of the youth group demonstrated how this process resulted in a sense of ownership of the service. Through the cyclical process they could bring their own practical experiences from the group into their further reflections and decisions on how they wanted to organise the service after the study period. In previous literature, this contribution is considered as one of the important advantages of action research, as it increases the possibility of a better utilisation of evaluation findings (Lincoln, 2001).

This "ownership-effect" appeared to be weaker in the participating organisation in the breast cancer study. The withdrawal by the collaborating organisation resulted in less dialogue between the researcher and the organisation, and thus, also fewer possibilities of rooting the program into the organisation. It is worth keeping in mind that this study was initiated in 2001, at a time in which the "hyperbole" of e-health (Seale, 2005) was salient both among health politicians and researchers in the field. We then experienced a "gap" between the initially assumed attractiveness of online self-help groups and how it was responded to by women with breast cancer. It is important to see the decreasing involvement by the organisation in this light. In 2004, when the second study was initiated, challenges related to the implementation of e-health services had become more apparent (Jadad \& Delamothe, 2004). The collaborating organisation in the youth study had, at this point in time, gained experience in the hosting of web-based services. This might have helped harmonise their expectations with the experiences of the online self-help group. It may be that the challenges related to the establishment of online services are better accounted for in contemporary efforts to establish such services. Thus, the gap between the expectations and the experiences made that became salient in the breast cancer study, might not have been as great if it had been 
initiated at a later date. The need for a close dialogue about the objectives of the program is further underscored through this experience.

Our third point in this discussion is that in spite of the benefits provided by the involved researcher, these two studies also demonstrate how ethical considerations are raised by the dual role of the researcher in action research. We have presented two cases in which the role as action researchers became challenging due to the need for further information and knowledge that could, in turn, be in conflict with our ethical responsibility. This conflict was of particular concern due to the involvement of people in a vulnerable situation and because of the physical distance to the people we were studying. Through the support from members of our reference groups however, we experienced that we were able to respond adequately to these situations. The examples illustrate how questions raised by the Regional Committee of Medical Research Ethics became relevant for the experiences made in the study. They throw an interesting light on an emerging debate in qualitative research, which addresses the relevance of the medical ethics tradition in participatory research (Oeye, Bjelland, \& Skorpen, 2007).

There are still additional dimensions of our dual role that call for attention. As described, some participants in the breast cancer study felt that they had to apologise for their absence in the group, and the researcher had to be aware and underscore the voluntary participation. Further, and perhaps more important to discuss, some of those who were regular users of both groups did assume a great deal of responsibility for the constitution of a friendly and supportive community. We must take into account the possibility that these efforts could be related to a felt obligation to satisfy the researcher. Even though our direct involvement in the group communication was at a modest level and related to particular topics, we were still the 
"leaders" of the groups and were in contact with some of the participants during a considerable period of time. This prolonged relationship might have the potential for contributing to a felt obligation to help us "succeed" with the online service. It illustrates a point made by Boser (2006) that the movement towards participatory research brings new sets of social relations for research "and, as such, presents a new set of ethical challenges" (p 9) that needs attention. At the same time, previous research has also demonstrated that a strong motive for research participation by bereaved and vulnerable people can be present, for example a wish to help others who are in a similar situation (Dyregrov, 2004). There is need for further knowledge on this issue in order to be able to assess the ethical risk related to the involved action researcher.

\section{Lessons learned}

We are left with two main experiences after conducting the two studies described in this article. First, we learned that the involved organisation's expectations to the program at issue need to be addressed and clarified. The program studied, online self-help groups, was scarcely explored and opened up for a range of expectations. In one of the studies, we experienced a gap between the involved organisation's expectations and how the program was responded to when introduced. This gap might have been somewhat counteracted through a better clarification of these expectations and discussion on this issue in an early phase of the study.

The second point is related to the first. Neither of the researchers was trained as leaders of self-help groups. On one hand, this provided a naivety towards the material that could be valuable. On the other hand, we felt that this experience could have made us better able to grasp and respond to the use of the group. 


\section{Conclusion}

The aim of this article was to provide more insight into advantages and challenges of conducting action research with the intention to improve health care. We have argued that action research enables the researcher to get particularly close to the socio-cultural processes that frame the introduction of new services. This dimension is valuable in contemporary health care, because new services are introduced into a complex field. Our argument is further that this deep access would have been difficult to acquire in a more distant role, for example as formative evaluators who were in a dialogue with health professionals or others that functioned as moderators of the groups. We have further illustrated how the approach can contribute to a sense of ownership towards the implemented program within the collaborating organisations. Some ethical challenges are still raised, for example that the sometimes prolonged relationship between the researcher and the participants in the study can produce a felt obligation to help the researcher to "succeed" with the program. Bearing these potential challenges in mind, our conclusion is still that action research offers an important contribution for the further development of health care services.

\section{Acknowledgements}

The breast cancer study was funded by The Norwegian Foundation for Health and Rehabilitation. The youth study was funded by the Northern Norway Regional Health Authority. Thanks to Sissel Eriksen for her constructive and insightful comments during our work with the article and to three anonymous reviewers for their constructive comments. Thanks also to Deede Gammon and Aksel Tjora for comments and Chris Hassenstab for language improvements. 


\section{Literature}

Alvesson, M., \& Sköldberg, K. (2000). Reflexive Methodology London: SAGE Publications Bar-Lev, S. (2008). "We are here to give you emotional support": Performing emotions in an online HIV/AIDS Support Group. Qualitative Health Research, 18(509-521).

Boser, S. (2006). Ethics and power in community-campus partnerships for research. Action Research, 4(1), 9-21.

Burawoy, M. (1998). The Extended Case Method. Sociological Theory, 16(1), 5-33.

Burrows, R., Nettleton, S., Pleace, N., Loader, B., \& Muncer, S. (2000). Virtual Community Care? Social policy and the emergence of computer mediated social support. Information, Communication \& Society, 3(1), 95-121.

Cook, T. (2006). Collaborative Action Research within Developmental Evaluation: learning to See or the Road to Myopia. Evaluation, 12(4), 418-436.

Cullen, J. (1998). The Needle and the Damage Done: Research, Action Research, and the Organisational and Social Construction of Health in the "Information Society". Human Relations, 51(12), 1543-1564.

Davison, K.P., Pennebaker, J.W., \& Dickerson, S.S. (2000). Who talks? The social psychology of Illness support groups. American Psychologist, 55(2), 205-217.

Dyregrov, K. (2004). Bereaved parents' experience of research participation. Social Science \& Medicine, 58, 391-400.

Evans, E., Hawton, K., \& Rodham, K. (2005). In what ways are adolescents who engage in self-harm or experience thoughts of self-harm different in terms of help-seeking, communication and coping strategies? Journal of Adolescence, 28(2005), 573-587.

Eysenbach, G. (2000). Recent advances: Consumer health informatics. British Medical Journal, 320, 1713-1716.

Eysenbach, G., Powell, J., Englesakis, M., Rizo, C., \& Stern, A. (2004). Health related virtual communities and electronic support groups: systematic review of the effects of online peer to peer interactions. British Medical Journal, 328(Special Issue May 2004).

Ferguson, T. (2000). Online patient-helpers and physicians working together; a new partnership for high quality health care. British Medical Journal, 321, 1129-1132.

Finne, H., Levin, M., \& Nilssen, T. (1995). Trailing research. A Model for Useful Program Evaluation. Evaluation, 1(1), 11-31.

Flicker, S., Maley, O., Ridgley, A., Biscope, S., Lombardo, C., \& Skinner, H. (2008). e-PAR: Using technology and participatory action research to engage youth in health promotion. Action Research, 6(3), 285-303.

Gavin, J., Rodham, K., \& Poyer, H. (2008). The Presentation of "Pro-Anorexia" in Online Group Interactions. Qualitative Health Research, 18(3), 325-333.

Gladstone Mc Connell, B., Boydell, K.M., \& McKeever, P. (2006). Recasting research into children's experiences of parental mental illness: Beyond risk and resilience. Social Science \& Medicine, 62(10), 2540-2550.

Hardey, M. (1999). Doctor in the house: The Internet as a source of lay health knowledge and challenge to expertise. Sociology of Health \& Illness, 21(6), 820-836.

Hardey, M. (2002). Life beyond the screen: embodyment and identity through the Internet. Sociological Review, 50(4), 570-585.

Hawton, K., Hall, S., Simkin, S., Bale, L., Bond, A., Codd, S., \& Stewart, A. (2003). Deliberate self-harm in adolescents: a study of characteristics and trends in Oxford, 1990-2000. Journal of Child Psychology and Psychiatry, 44(8), 1191-1198.

Jadad, A., \& Delamothe, T. (2004). What next for electronic communication and health care. British Medical Journal, 328(Special Issue 15 May), 1143-1144. 
Johnsen, J.-A.K., Rosenvinge, J.H., \& Gammon, D. (2002). Online group interaction and mental health: An analysis of three online discussion forums. Scandinavian Journal of Psychology, 43, 445-449.

Khanlou, N., \& Peter, E. (2005). Participatory action research: considerations for ethical review. Social Science \& Medicine, 60, 2333-2340.

Klemm, P., Bunnell, D., Cullen, M., Soneji, R., Gibbons, P., \& Holecek, A. (2003). Online cancer support groups, a review of the research literature. Computers, Informatics, Nursing, 21(3), 136-142.

Kummervold, P.E., Gammon, D., Bergvik, S., Johnsen, J.-A., Hasvold, T., \& Rosenvinge, J.H. (2002). Social support in a wired world. Use of online mental health forums in Norway. Nordic Journal of Psychiatry, 56(1), 59-65.

Kvale, S. (1996). Interviews: An introduction to qualitative research interviewing. Thousand Oaks, CA:SAGE.

Ladkin, D. (2007). Action Research. In C. Seale,G. Gobo,J. Gubrium, \& D. Silverman (Eds.), Qualitative Research Practice. London: SAGE publications.

Lieberman, M., \& Russo, S (2001). Self-help groups and the Internet; breast cancer newsgroups. International Journal of Self Help and Self Care, 1(4), 323-334.

Lieberman, M., \& Goldstein, B. (2005). Not all negative emotions are equal; the role of emotional expression in online support groups for women with breast cancer. Psychooncology, 15(2), 160-168.

Lincoln, Y. (2001). Engaging sympathies: Relationships between Action research and Social Constructivism. In P. Reason, \& H. Bradbury (Eds.), Handbook of Action Research. Participative Inquiry and Practice. London: SAGE.

Mordoch, E., \& Hall, W. (2002). Children Living With a Parent Who Has a Mental Illness: A Critical Analysis of the Literature and Research Implications. Archives of Psychiatric Nursing, XVI(5), 208-216.

Morrison, B., \& Lilford, R. (2001). How Can Action Research Apply to Health Services? Qualitative Health Research, 11(4), 436-449.

Nock, M.K., \& Teper, R. (2007). Psychological Treatment of Self-Injury Among Adolescents Journal of Clinical Psychology 63(11), 1081-1089.

Oeye, C., Bjelland, A.K., \& Skorpen, A. (2007). Doing participant observation in a psychiatric hospital - Research ethics resumed. Social Science \& Medicine, 65, 22962306.

Olsen, O., \& Lindøe, P. (2004). Trailing Research Based Evaluation: Phases and Roles. Evaluation and Program Planning, 27(4), 371-380.

Patton, M.Q. (1990). Qualitative Evaluation and Research Methods. Second Edition Newsbury Park: SAGE.

Payne, G., \& Williams, M. (2005). Generalization in Qualitative Research. Sociology, 39(2), 295-314.

Reason, P., \& Bradbury, H. (2006a). Introduction: Inquiry and Participation in Search of a World Worthy of Human Aspiration. In P. Reason, \& H. Bradbury (Eds.), Handbook of Action Research. Newsbury Park, California: SAGE.

Reason, P., \& Bradbury, H. (2006b). Preface. In P. Reason, \& H. Bradbury (Eds.), Handbook in action research. Newsbury Park, California: SAGE.

Rier, D. (2007). Internet support groups as moral agents: the ethical dynamics of HIV+ status disclosure. Sociology of Health \& Illness, 29(7), 1043-1058.

Rutter, M., \& Quinton, D. (1984). Parental psychiatric disorder: Effects on children. Psychological Medicine, 14, 853-880. 
Sandaunet, A-G. (2008). The challenge of fitting in: non-participation and withdrawal from an online self-help group for breast cancer patients. Sociology of Health \& Illness, 30(1), 131-144.

Sandaunet, A-G. (in press). A space for suffering? Communicating breast cancer in an online self-help context. Qualitative Health Research.

Sandelowski, M. (2004). Using Qualitative Research. Qualitative Health Research, 14(10), 1366-1386.

Seale, C. (2005). New directions for critical internet health studies: representing cancer experience on the web. Sociology of Health \& Illness, 27(4), 515-540.

Shapiro, S., Lopez, A., Scwarz, G., Bootzin, R., Figueredo, A., Braden, C., \& Kurker, S. (2001). Quality of Life and Breast Cancer; Relationship to Psychosocial Variables. Journal of Clinical Psychology, 57(4), 501-519.

Silverman, R.M., Taylor, H.L., \& Crawford, C. (2008). The role of citizen participation and action research principles in Main Street revitalization: an analysis of a local planning project. Action Research, 6(1), 69-93.

Skinner, H., Biscope, S., \& Poland, B. (2003). Quality of internet access: barrier behind internet use statistics. Social Science \& Medicine, 57(5), 875-880.

Smith, M. (2004). Parental mental health: disruptions to parenting and outcomes for children. Child and Family Social Work, 9, 3-11.

The Ministry of Health and Social Affairs (2001). "Say@" Electronic interaction in the health and social sector, public programme for electronic interaction in health care 20012003 (Si@! Elektronisk samhandling i helse-og sosialsektoren, statlig tiltaksplan for elektronisk samhandling i helse- og sosialsektoren 2001-2003), The Ministry of Health and Social Affairs: Trykksakekspedisjonen.

The Regional Committees for Medical Research Ethics in Norway (2006). (http://www.etikkom.no/english)

Till, J.E. (2003). Evaluation of support groups for women with breast cancer: importance of the navigator role. Health and Quality of Life Outcomes, 16(1).

van Eyk, H., Baum, F., \& Blandford, J. (2001). Evaluating Health Care Reform: The Challenge of Evaluating Changing Policy Environments. Evaluation, 7(4), 487-503.

Waldron, V., Lavitt, M., \& Kelley, D. (2000). The Nature and Prevention of Harm in Technology-Mediated Self-Help Settings: Three exemplars. Journal of Technology in Human Services, 17(2/3), 267-293.

Walther, J.B., \& Boyd, S. (2002). Attraction to computer-mediated social support. In C.A. Lin, \& D. Atkin (Eds.), Communication technology and society: Audiences adoption and uses of the new media. New York: Hampton Press. 